\title{
$\operatorname{arCOS} D E S I G N$
}

\section{O Diagrama e o design da informação na arquitetura contemporânea}

Ana Paula Rocha (UNICAMP, Brasil)

apaularocha@yahoo.com.br

Avenida Albert Einstein, 951, Cidade Universitária Zeferino Vaz

Campinas, SP. CEP: 13083-852

Daniel de Carvalho Moreira (UNICAMP, Brasil)

damore@fec.unicamp.br 


\title{
O Diagrama e o design da informação na arquitetura contemporânea
}

Resumo: Repensar a representação diagramática do processo de design arquitetônico significa considerar a informação não como dados estatísticos, mas como um operador da relação entre os objetos, os conteúdos e as pessoas - especialmente sob a influência tecnologias digitais. A análise apresentada neste artigo baseia-se no desempenho do estúdio de arquitetura holandês chamado MVDRV e o desenvolvimento de softwares paramétricos, como o Functionmixer, que utiliza a prática do design para traduzir in-formação.

Palavras-chave: diagramas; design da informação; software paramétrico.

\section{Diagram and Information Design in Contemporary Architecture}

\begin{abstract}
Rethink the diagram representation in the architectural design process means consider the information not as statistical data, but like an operator of the relationship between objects, contents and people - specially under the Digital Technologies influence. The analysis presented in this paper is based on the architectural studio performance of the Dutch group named MVDRV and the development of parametric softwares, such as Functionmixer, to the design practice translate in-formation.
\end{abstract}

Key words: diagrams; information design; parametric software. 


\section{Introdução}

Entender as relações humanas em um ambiente tecnológico interativo, de sinais eletrônicos, informações e comportamentos dinâmicos, requer a compreensão de conhecimentos e habilidades para desenvolver interfaces. A Revolução Industrial e, por conseguinte, o advento da idade moderna, serviu como cenário para a experiência de um tempo cronometrado, medido e organizado. A Revolução Tecnológica vivida na atualidade destrói essa ideia de tempo, inaugurando uma relação atemporal das relações sociais e culturais. O nosso seria um tempo de dissolução dos elementos que há pelo menos três séculos têm constituído a base temporal para a compreensão dos processos sociais (AUGUSTO, 1998, p.27). Sem dúvida, essa constatação sugere estar em curso uma "re-significação do tempo", caracterizada por uma crescente desvalorização cultural do passado, uma progressiva perda de perspectiva e de esperança em relação ao futuro causada pelo excesso de informações, e uma "acentuação exasperada da vivência de um presente" (AUGUSTO, 1998, p.28), preenchido exaustivamente.

O tempo percebido pelo indivíduo perde sua linearidade, fazendo com que a relação passado-presente-futuro, que representa um tempo cronológico, dê lugar a "um tempo que se expõe instantaneamente"(virilio, 1995, p.43), no qual resta apenas a vivência repetida do agora, a busca desenfreada do momento atual. Essa ideia de atemporalidade não elimina as conquistas modernas, mas sim, sugere uma "hibridação com o tempo digital" (virilio, 1995, p.57).

A incorporação do tempo na arquitetura introduz um fator de ambigüidade ou indeterminação que "subverte a identidade entre a função e a forma" (virilio, 1995, p.57). O que ocorre é que a forma do edifício tem que dar lugar a distintas funções, por exemplo, em um mesmo dia. O tempo varia a estrutura do edifício, faz com que sua topografia interna se converta em variável, instável durante o uso.

A condição de mudança e de mobilidade constante é elemento constitutivo da realidade atual, apontando a substituição da forma pelo evento. Não podemos mais falar em uma arquitetura predeterminada por suas funções e rígida, que gera o caminhar dos eventos do homem. Essa concepção arquitetônica que parte da interação cotidiana e instantânea do homem com o espaço deve se estabelecer a partir de uma flexibilização que possibilite a substituição de uma situação por outra, regida pelo sistema de retroalimentação (feedback contínuo).

Não é mais possível ver o espaço como objeto estático, artefato do projeto e da construção ou resultado de necessidades programáticas imediatas, congeladas e materializáveis em um determinado sítio físico, adequado em razão de determinada relação indivíduo-ambiente. 
Partindo do princípio que a informação construída pelos sujeitos é própria da produção do espaço contemporâneo, entende-se que essa mudança legitima o projeto a tornar-se procedimento (sORIANO, 2009, p.12), considerando a informação não como dado estático, mas como operadora das relações entre objetos, conteúdos e sujeitos.

É preciso repensar o processo de concepção de projetos a partir do ponto de vista da influência da ideia de atemporalidade atual, que interfere diretamente no comportamento do homem contemporâneo, para que os edifícios correspondam, materialmente, à imaterialidade inerente à inserção das tecnologias digitais no cotidiano humano.

Esse objetivo pode ser alcançado através da inserção de tais tecnologias nos processos de projetos arquitetônicos por diagramas e, nesse sentido, o trabalho do grupo de arquitetos holandeses Winy Maas, Jacob van Rijs e Nathalie de Vries - que integram o atelier internacional de arquitetura MVDRV - insere-se no panorama composto por profissionais que estudam e tentam compreender os processos decorrentes da era digital, incorporando-os à prática projetual.

\section{Integração do Computador no Processo de Projeto}

Desde o final da década de 1990, os arquitetos estão posicionando suas práticas sob uma estratégia que combina a coleta, processamento e interpretação de grande quantidade de dados, o que significa a conversão de informação estatística em forma concreta e inventiva.

A readequação de processo de projeto, frente às imposições das novas tecnologias, é necessária para entender e incorporar as alterações dos modos de ser e viver na esfera de um mundo que tem a tecnologia digital como elemento norteador.

A partir dessa demanda, o escritório MVDRV desenvolveu um software paramétrico, o Functionmixer, que constitui o estudo de caso aqui apresentado. Este estudo insere-se dentro do contexto tecnológico e cultural, no qual estão inseridos os processos digitais nos projetos arquitetônicos. Sua análise foi embasada pelas discussões contemporâneas acerca do uso de diagramas em arquitetura, concebidos sob o desenvolvimento de modelos parametrizáveis.

Nesse contexto, insere-se o software Functiomixer, um programa desenvolvido pelo escritório holandês MVDRV para projetar espaços urbanos multifuncionais, em oposição às tradicionais soluções urbanísticas monofuncionais holandesas (CECília, 2002, p.28). O software faz contínuos intercâmbios de funções e registra os resultados em um diagrama com índices de pontuação, sendo que, os valores de cada um dos parâmetros relacionados são fundamentais para a formulação dos possíveis modelos. 


\section{Diagrama contemporâneo: parametrização de dados}

O conceito de diagrama não é novo, é um conceito inerente à arquitetura quando entendido como recurso gráfico de representação de informações (sOMOL, 1999, p.43). Entretanto, mesmo não sendo uma novidade em arquitetura, o diagrama tem recebido considerável destaque.

$\mathrm{O}$ discurso do diagrama do século $\mathrm{xx}$ foi forjado na ideologia moderna sob uma concepção racionalista cujo principal critério seria a instrumentalidade. Um código discursivo que organizava a realidade para sua utilização e seu entendimento mais básico era utilizado para o controle do layout, da planta e do usuário, cujo princípio operacional foi funcionalizar o espaço e "espacializar" a função (DUARTE, 2012, p.13).

Ainda que opondo-se à ideologia moderna, a crítica pós-moderna também atingiu o discurso do diagrama, mas incorporou a ele um novo significado. Um nome chave para entender esta transformação é Peter Eisenman, que desde 1963 com sua tese "The Formal Basis of Modern Architecture" (somol, 1999, p.17), utiliza o diagrama para tratar de forma e linguagem, construindo um caminho para a superação do dilema da arquitetura moderna através de um novo tipo de diagrama não mais determinístico e nem linear, em oposição à leitura funcionalista.

O entendimento de que o diagrama não é apenas uma explanação ou desenho explicativo, coloca-o como agente intermediário no processo de geração do espaço-tempo real (somoL, 1999, p.18).

De modo geral, os diagramas contemporâneos são representações gráficas de referências projetuais, informações do programa arquitetônico gerenciadas pelo computador, características urbanas e sócio-econômicas do território de inserção da obra e meios visuais que evidenciam e condensam dados a serem manipulados em projeto. Na cultura arquitetônica atual, a concepção se reinventa, o projeto parte da análise e da crítica do existente, o diagrama corresponde à chamada "Cultura do Projeto" (DuARte, 2012, p.23). Afinal, o debate sobre o diagrama trouxe à tona a velha discussão da tipologia, mas em condições novas, apoiando-se nos modelos paramétricos e nas novas formas dos meios digitais (BRAHAM, 2000, p.21).

A aproximação às tecnologias digitais e a linguagem por dígitos sempre em atualização, permite sonhar com o registro das efemeridades do mundo diário percebido pelo homem. O que anteriormente era considerado "influência" para os projetistas gerarem uma solução para um problema, agora são mapeados sinteticamente como informação topográfica direta (DUARTE, 2012, p.26). Na tentativa de captar este movimento, os arquitetos elegem parâmetros e registram suas alterações, sejam estes mudanças do vento, do ruído local, do tráfego de carros ou tendências demográficas. 
Em depoimentos de vários arquitetos e escritórios contemporâneos, presentes no livro "Archilab's: Future House" (BRAYER, 2002, p.97), atesta-se o uso do diagrama como um instrumento gráfico de pensamento associado à arquitetura como procedimento:

(1) Manuel Gauza, arquiteto espanhol do escritório Actar, afirma estar interessado em combinar eprocessar "layers" de informações referentes ao contexto, tanto local e social quanto global e cultural, gerando uma arquitetura diagramática assentada em mapas de relações estratégicas e trajetórias cartográficas. Assim, o diagrama, para o arquiteto, é materialização de informações e movimentos e não a especulação de ideias e gestos.

(2) Ian+, escritório italiano, entende o diagrama em seu processo projetual como oportunidade deexplorar relações e experienciar processos. É um mapa capaz de documentar um número infinito de trajetórias, tornando-se uma máquina de ações sintéticas (diagnóstico e leitura) e produtivas (resposta). Ou, em outras palavras, um sistema de organização de informações.

(3) Launchpad05, coordenado pelo tailandês Takuya Onishi, considera que o diagrama não representa apenas o sistema físico, mas também o social. Nesse caso, um sistema social adequado, que torna o espaço arquitetônico, economicamente, tecnicamente, automaticamente, socialmente e naturalmente próprio do lugar.

(4) nArchitects, escritório americano, revela o que seja diagrama dentro de três estágios: generativo (como um mecanismo que produz novos conceitos arquitetônicos); comunicativo (como um veículo para esclarecer, redimensionar e editar conceitos); e, operacional (como plano de ação). Diagramar torna-se um processo contínuo, desde o projeto até a construção, "informado por" e "informando" decisões espaciais específicas.

(5) UNstudio, representado pelo arquiteto holandês Ben van Berkel, vê o diagrama como mediador, um elemento externo entre o sujeito e o objeto, com o objetivo de escapar das tipologias pré-existentes que não correspondem às demandas e situações contemporâneas. Para o arquiteto, é um processo técnico e não conceitual. Sendo assim, a inovação e inspiração arquitetônicas vinculam-se mais à operação do que ao conceito.

(6) Vincent Guallart, arquiteto espanhol, é interessado nos diagramas como elementos organizadores do espaço, isto é, revelam a essência das relações das coisas. 
(7) YoungJoon Kim, arquiteto do escritório coreano Yo2, afirma que as reais questões da arquitetura são baseadas na noção de organização e não formalização; arquitetura como formação e não forma. Nesse sentido, o croqui convencional é abandonado pelo arquiteto dando lugar ao diagrama-ferramenta que abre possibilidades para estabelecer lógicas e organizar questões.

Se o diagrama na arquitetura moderna é instrumento útil de representação de informações (programa, organização e distribuição), na arquitetura contemporânea é instrumento instigante de análise de informações na medida em que essas não só são representadas, mas também processadas, manipuladas e transformadas. Condensam informações, mas não as reduzem. O diagrama é uma linguagem que conecta informações e suas relações, bem como as interações entre tempo e espaço, comunicando potencialidades e aceitando modificações. A arquitetura gerada revela-se como um medium que carrega informação ou um medium informacional, ao contrário da forma pré-concebida como objeto plástico (soriano, 2009, p.43).

A formação de modelos parametrizáveis tem sido o passo seguinte, um objeto que se transforma segundo os valores dos parâmetros. Tal liberdade presente na possibilidade de ter todas as variações programadas torna-se, ao final, o desenho e seu controle.

Essa concepção de diagrama influencia diretamente o trabalho do escritório MVDRV, no qual o processo de projeto por diagramas se desenvolve sob o conceito de 'datascape', que corresponde a uma paisagem de dados, isto é, dados e eventos conformam elementos dinâmicos que transformam a paisagem arquitetônica - e, em última instância, a paisagem urbana. O processo passa, por essa concepção, a centrar-se na interação de dados e eventos que ocorrem no espaço arquitetônico. Sua pesquisa e processo de projeto enfocam o uso de softwares paramétricos de acordo com dois aspectos fundamentais que qualificam sua produção: a investigação e o potencial criativo conceitual.

\section{Functionmixer: software paramétrico diagramando funções}

O escritório MVDRV iniciou seus trabalhos em Rotterdam em 1993 e vem dedicando vários esforços à prática da investigação projetual desde o início de sua trajetória. O trabalho de Maas, Jacob van Rijs e Nathalie de Vries combina prática e investigação atuando num sistema de retroalimentação, em que os estudos teóricos geram produtos arquitetônicos, ao mesmo tempo em que os processos de projeto produzem análises teóricas. 
Essa característica do grupo fica evidente quando se analisa a criação do software Functionmixer, que foi o primeiro programa desenvolvido pelo escritório com o objetivo de otimizar as tomadas de decisão provenientes de municipalidades, planejadores e grupos de habitantes no desenvolvimento de bairros de uso misto e projetos multifuncionais. Segundo os arquitetos holandeses, a materialização do edifício de apartamentos Silodam, ilustrado na figura 1 suscitou questões sobre a necessidade de mesclar funções nos espaços urbanos e assim, eles idealizaram e desenvolveram o software para conseguir trabalhar com um grande número de informações, desenvolver hipóteses e visualizá-las (CECílıA, 2002, p.27).

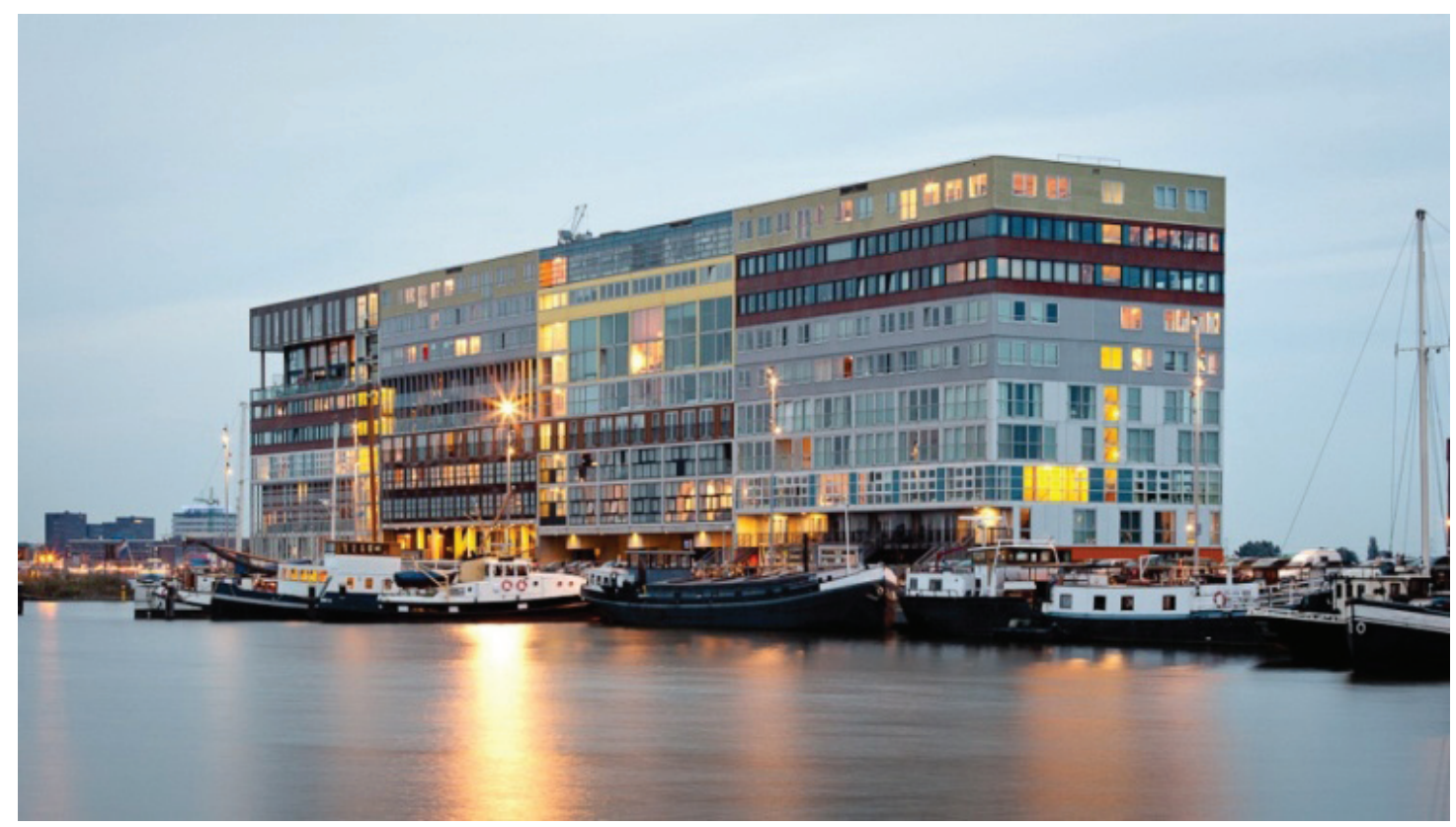

Figura 1. Edifícios de Apartamentos Silodam. Fonte: (CECília; LeVene, 2002, p. 28).

Para estudar possíveis soluções de projeto para o problema da monofuncionalidade urbana, era preciso desenvolver um modelo que oferecesse soluções adequadas às complexas exigências da mescla de funções. Exigências que demandavam um aumento de densidade, intensidade e diversidade em relação às políticas e normas ambientais, econômicas e sociológicas, tanto fixas como variáveis.

Nesse contexto, que decidiu que um modelo para mesclar funções deveria se constituir, essencialmente, de um indicador de mudança dos parâmetros espaciais quantitativos - densidade e diversidade funcional - de acordo com os parâmetros qualitativos - sustentabilidade ambiental, economia e saúde social (CECília, 2002, p.26). 
O Functionmixer funciona como um produto dinâmico, um processo e não um resultado fixo e estático; oferece liberdade de escolha dentro de alguns parâmetros determinados e permite que se faça uma idealização física e espacial. O programa pode manipular dados em grandes quantidades e com grande complexidade - incluindo alguns invisíveis, como o ruído ou as dimensões econômicas. Em outras palavras, ele constrói um mundo abstrato que representa, em certa medida, a cidade e otimiza a disposição das funções urbanas de acordo com os objetivos estabelecidos por clientes e arquitetos.

Na versão de demonstração do software, foram criados doze parâmetros pré-definidos, tendo cada uma deles uma função específica na localização das funções. Os arquitetos mostraram que os usuários do programa podem combinar os parâmetros e mudar sua ordem de importância, possibilitando que diferentes cidades surgissem da otimização. Os usuários podem seguir o processo de otimização na tela, onde a cidade é renderizada continuamente como um modelo 3-D de realidade virtual. Além dessa maquete eletrônica, existe um diagrama numérico de medições que realiza uma avaliação objetiva das cidades otimizadas (CEcília, 2002, p.26), como está ilustrado na figura 2.

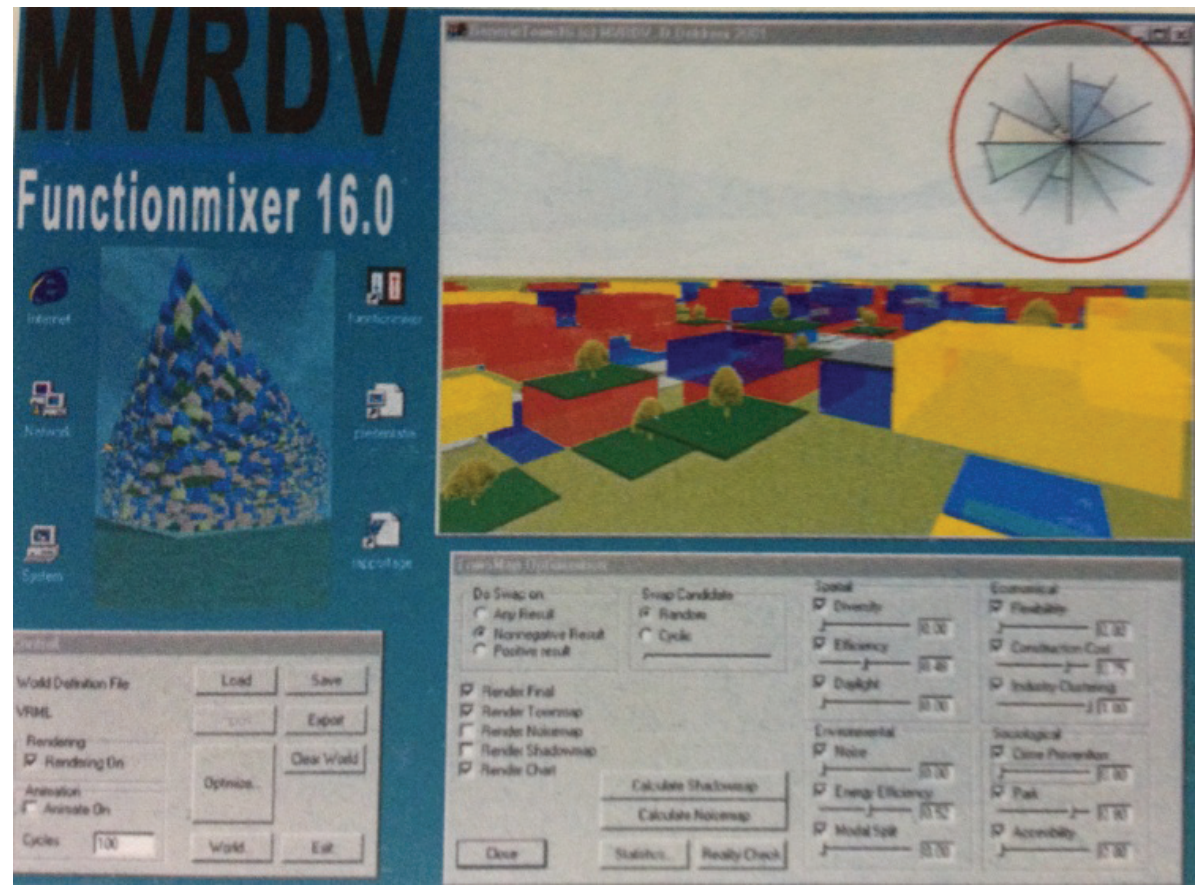

Figura 2: Ambiente virtual do Functionmixer - renderização 3-D e diagrama numérico. Fonte: (CECÍLIA; LEVENE, 2002, p. 26).

Um dos primeiros casos simulados e apresentados pelo grupo holandês é mostrado na figura 3. Na descrição das representações tridimensionais os arquitetos explicam que, em uma zona fictícia de projeto, foram otimizados 
três casos utilizando o programa de necessidades solicitado e um coeficiente de edificabilidade (que corresponde à densidade populacional).

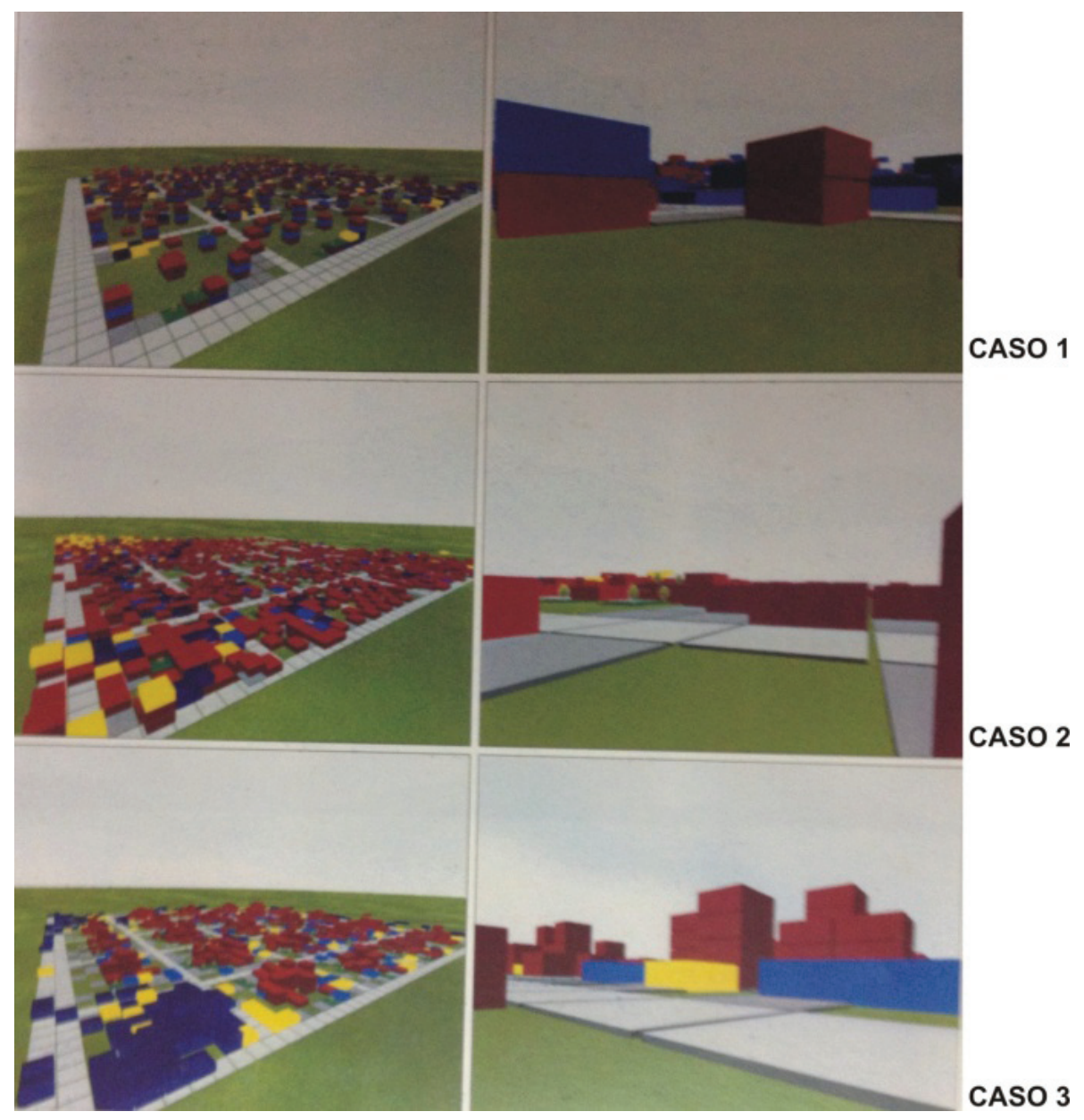

Figura 3: Simulação da inserção de dados no Functionmixer.

Fonte: (CECÍLIA; LEVENE, 2002, p. 27)

No CASO 1, busca-se um contorno heterogêneo aplicado de modo uniforme. Nesse caso, a luz desempenha um papel importante na otimização para definir os limites por contraste. No CASO 2, acrescenta-se a separação ou ruptura que provoca uma atração de pixels que contenham grandes quantidades de ocupantes. Esses pixels se colocam na seguinte hierarquia: serviços, oficinas e casas. Os custos da construção e a eficiência energética têm um papel decisivo no CASO 3 - e deles derivam as agrupações separadas de funções -, as indústrias de segunda e terceira categorias, por exemplo, são movidas para a parte frontal das esquinas.

Desse modo, o Functionmixer é um modelo heurístico que permite encontrar uma otimização em um mar de possíveis desenhos sendo que, o projeto 
final é um resultado diagramático que cumpre os requisitos dos parâmetros que foram previamente definidos.

\section{Conclusão}

O estudo do Functionmixer evidencia como a diagramação, trabalhada sob o conceito contemporâneo de desenvolvimento de softwares paramétricos, está em acordo com a temporalidade exacerbadamente acelerada das transformações in-formacionais experimentadas pela sociedade atual.

O método desenvolvido pelos arquitetos que compõem o escritório de arquitetura holandês MVRDV, foi criado com o objetivo de encontrar soluções a um problema. É um procedimento simplificador, embora não simplista que, em face a questões difíceis, envolve a substituição destas por outras de resolução mais fácil a fim de encontrar respostas viáveis, ainda que imperfeitas. Tal procedimento pode ser visto tanto como uma técnica deliberada de resolução de problemas, como uma operação de comportamento automática, intuitiva e inconsciente.

O inegável é que por meio desse processo de projeto é possível visualizar o excesso de informação - que é inerente aos modos de vida contemporâneos -, categorizar e sistematizar parâmetros que interferem direta e indiretamente no problema, processá-los e diagramá-los; de forma que a complexidade e a velocidade de transformações impostas pelas Tecnologias da Informação e Comunicação (TIC's) possam ser traduzidas em um produto que responde às questões que são discutidas e inerentes ao mundo digital.

A arquitetura na era digital é formada por oscilações numéricas binárias que compõem imagens e imaginário. Toda a complexidade que o excesso de dados e informações impõe ao imaginário encontra, no ciberespaço, um campo fértil para a especulação e reflexão, onde facilmente se pode ensaiar, modificar e simular formas complexas através de simulações que, de outra maneira, permaneceriam estáticas.

Assim, o uso de diagramas na forma de programas informáticos como instrumento de projeto para arquitetos e urbanistas, que têm missões multidisciplinares, não só desperta indagações, mas também aponta possíveis direções para o futuro da prática projetual. 


\section{Referências}

AUGUSTO, M. H. O. Temporalidade, Individualidade e Ordem Social. Dissertação de Mestrado. Departamento de Sociologia. Universidade de São Paulo, São Paulo, 1998.

BRAHAM, W. After Typology: The Suffering of Diagrams. In: Architectural Design, 70.3, 2000: 9-11.

BRAYER, Marie-Ange; SIMONOT, Béatrice. Archilab's Future House Radical Experiments in Living Space. Orléans: Thames \& Hudson, 2002.

CECÍLIA, Fernando Márquez; LEVENE, Richard, eds. - "MVRDV 1997-2002". El Croquis, $\mathrm{n}^{0}$ 111, Madrid: El Croquis editorial, 2002: 11, $26-29$

DUARTE, Rouvenir Bertola. Radicalizando por diagramas - Por Favor, Devagar no Mar Agitado das Novidades. In: Vitruvius, 143.06, abril, 2012.

MAAS, W.; Van Rijs, J.; Koek, R. KM3 Excursions on Capacities. Barcelona: Actar, 2005.

VIRILIO, P. O Espaço Crítico. Rio de Janeiro: Editora 34, 1995.

SOMOL, R. E. Peter Eisenman Diagram Diares. London: Thames \& Hudson, 1999.

SORIANO, F. 100 Hiperminimos. Madrid: Lampreave Asociados, 2009. 
Recebido em: 30/04/2014

Aceito em: 01/06/2014

\section{Como citar}

ROCHA, Ana Paula; MOREIRA, Daniel de Carvalho. O Diagrama e o design da informação na arquitetura contemporânea. Arcos Design. Rio de Janeiro: PPD ESDI - UERJ. Volume 8 Número 1 Junho 2014. pp. 49-61. Disponível em: [http://www.e-publicacoes.uerj. br/index.php/arcosdesign]

\section{DOI}

http://dx.doi.org/10.12957/arcosdesign.2014.13082

\section{(c) (1) (2)}

A Revista Arcos Design está licenciada sob uma licença Creative Commons Atribuição - Não Comercial - Compartilha Igual 3.0 Não Adaptada. 